\title{
ADAPTING STRUCTURATION THEORY TO UNDERSTAND THE ROLE OF REFLEXIVITY: PROBLEMATISATION, CLINICAL AUDIT AND INFORMATION SYSTEMS
}

\author{
Laurence Brooks $^{+}$, Chris Atkinson ${ }^{*}$ and David Wainwright ${ }^{\$}$ \\ ${ }^{+}$Corresponding Author \\ Department of Information Systems and Computing \\ Brunel University, Kingston Lane, Uxbridge, Middlesex, UB8 3PH, UK. \\ Email: Laurence.Brooks@brunel.ac.uk \\ *Manchester Business School, University of Manchester, Manchester, UK \\ Email: Christopher.Atkinson@manchester.ac.uk \\ ${ }^{\$}$ School of Computing, Engineering and Information Sciences, Northumbria \\ University, Newcastle upon Tyne, NE2 1XE \\ Email: David.Wainwright@ northumbria.ac.uk
}

Abstract

This paper is an exploratory account of the further development and application of a hybrid framework, StructurANTion, that is based on Structuration and Actor Network Theories. The use of social theories in general and their use in information systems research in particular is explored leading to the use of the framework to examine the concept of what are termed humanchine networks in the context of clinical audit, within a healthcare Primary Care Trust. A particular focus is on the manner in which information systems based reflexivity contributes to both entrenching a networks' structurated order as well as contributing to its emancipatory change. The case study compares clinic-centric and patient-centric audit and seeks to further extend the understanding of the role of information and information systems within structurated humanchine activity systems. Conclusions indicate that the use of more socially informed IS methods and approaches can incorporate more emancipatory ideals and lead to greater adoption and usage of more relevant and useful clinical information systems and practices. 
Keywords: clinical audit, reflexivity, Social Theory, Structuration Theory, Actor Network Theory, StructurANTion Theory, humanchine, structurated networks, healthcare, Information Systems

Word count: 6932 


\section{INTRODUCTION}

The past decade has seen a systematic shift within healthcare away from paper patient records stored locally, in hospitals or GP practices, to Electronic Patient Records (EPR) accessible anywhere across the English National Health Service. This has been facilitated by the National Project for Information Technology (NPfIT) now known as Connecting for Health (http://www.connectingforhealth.nhs.uk/about/governance/), a government organisation that has resulted in linking all healthcare provider organisations together across the country onto a single data spine.

The ready availability of the EPR has facilitated a rapidly growing emphasis on clinical audit, directed towards the continuous improvement of patient care across England and Wales. Information Systems (IS) and technologies have facilitated this and are now critical to the current operational efficiency and future strategic development of the healthcare system. One major strategic aim is to improve the delivery of care by clinicians whilst continuing to enhance the effective management of resources within increasing financial constraints. However a major factor to be addressed will be the empowerment of the patient with respect to them taking control of the health services provided to them (often described as providing 'patient choice').

A problem exists over decision making and choice however, in that the patient is not put actively at the centre of the auditing process; they are the object of clinical audit but it is the clinician who initiates the audit, undertakes it and uses its outcomes to further their clinical practices. In turn this adds to the maintenance of their status as being the most powerful class of actors within the medical health system. A complex duality occurs whereby the clinicians and other actors continually utilise and interact with information technologies and systems in order to use, maintain and further develop the audit process. This complex interaction between humans and technology is poorly understood by the actors involved in the clinical audit process including managers, policy makers, information professionals and academics researchers alike.

The context for this paper is an exploration of the role of reflexivity as a process that is enhanced or inhibited by the duality of interaction that occurs between clinical 
professionals, information systems and technologies. This builds on a cumulative programme of work by the authors (Atkinson and Brooks, 2003; 2005; Brooks and Atkinson, 2004; Brooks, 1997; Waring and Wainwright, 2002) to develop new approaches to information systems design, implementation, adoption and use that incorporate greater emancipatory ideals. The focus of the present study is the development of a framework based on Structuration Theory (Giddens, 1984; 1991) and Actor Network Theory (Callon, 1986; Law and Hassard, 1999). This paper aims to further develop this framework, termed StructurANTion (Brooks and Atkinson, 2004) as a tool for information systems research and explore its potential impact on the process of reflexivity and emancipatory clinical practice. These aims respond both to the growing maturity of research studies utilising Structuration and Actor Network approaches and the need for further empirical studies exploring more critical adaptations of the approach to better understand information systems - seen as constituted by the duality of interactions caused by human agency, technology and structure (Jones and Karsten, 2008). It is anticipated that the work will contribute to future design theories of information systems (Gregor and Jones, 2007) and will assist healthcare information systems and clinical professionals engaged in implementing audit and control systems.

The first section of the paper provides a brief outline of Structuration Theory (ST) based on the initial work of the social theorist Anthony Giddens including its current adaptation within IS research. Actor Network Theory is then discussed as a complementary theory to Structuration leading to the third section which provides a rationale and brief history of the development and emancipatory focus of the adapted framework, termed StructurANTion. In the fourth section, this is used as a theoretical framework to explore the role of reflexivity and emancipator practices in a process of clinical audit within a Primary Care Trust (PCT) organisation healthcare context. The duality of interactions between agency, structure, humans and technologies (what we have called a 'humanchine' network) is then further discussed. The final section then concludes with an assessment of the developed theory for future IS research and its potential to enhance current audit processes and practices in healthcare systems. 


\section{STRUCTURATION THEORY: AN OUTLINE}

Structuration theory offers an ontology that accounts for how societies - and it is argued here organisations - both exist, persist and change across time and space. The social system, for Giddens (Giddens, 1979; Giddens, 1984; Giddens, 1991), is recursively (re)created as a result of its human actor's knowledgeable actions and interactions over time and space; drawing on social structures and so recursively (re)creating both those structures and society itself across a time and space of its own making. Anthony Giddens identifies social structures as being Signification, Legitimation, and Domination. Through their respective real world 'modalities', these social structures enable people to firstly 'Communicate' with each, secondly be socially 'Sanctioned' in their actions and interactions and, thirdly, have Power over other human agency and non-human resources, authorizing respectively a persons' agency and allocating recourses. Humans draw upon each structure's modalities in their acting and interacting with others. These modalities are respectively: for communication Interpretive Schemes based on the persons' stocks of knowledge and a facility with language; Norms that provides the individual with social rights, while also imposing on them social obligations to act in certain ways under particular conditions; and finally a Facility for authorising other peoples' behaviours and the allocation of non-human material resources in achieving some form of agency through an exercise of power (see Figure 2).

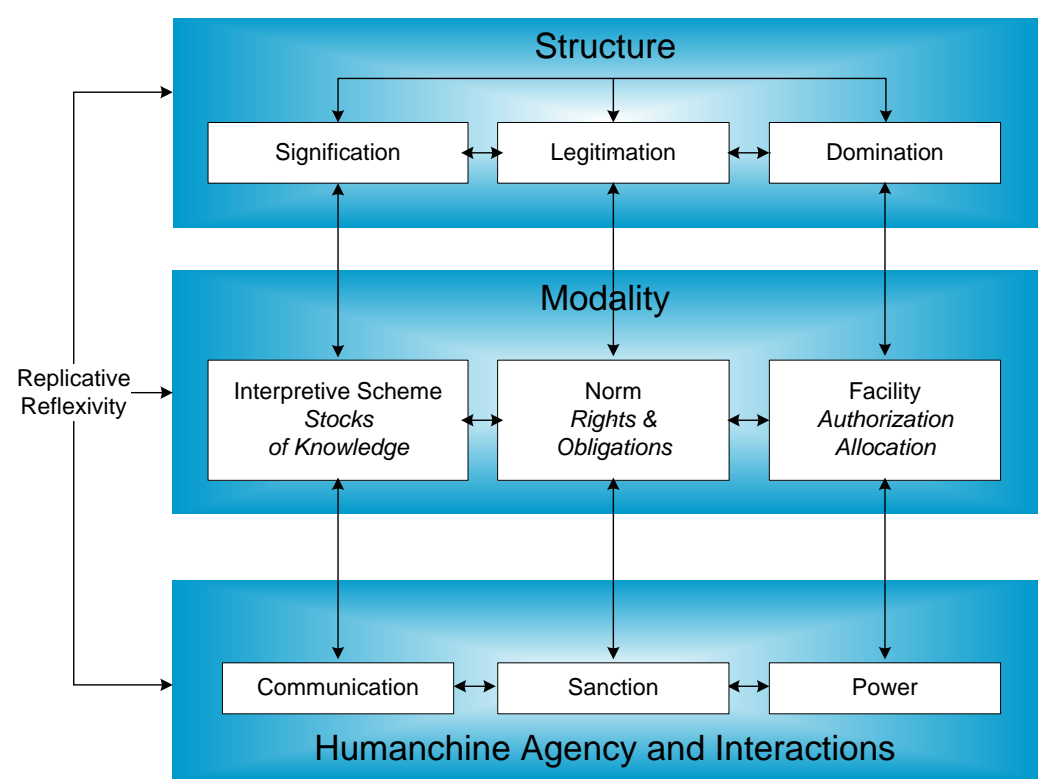

Figure 1

Giddens' Theory of Structuration (Giddens, 1984; Giddens, 1991) 
An individual person's actions and interactions with others are facilitated through a melding of these commonly shared structural modalities. These are drawn on from the persons' 'practical consciousness' which enables and informs them about how to act under specific social circumstances. In doing this, through their motivated actions they recursively (re)create society as an emergent property of both their inner psychological and their external societal world of social interaction. By drawing on these structures and their modalities in order to act and interact they both replicate the existing structures and incrementally change them. Thus society emerges, persists and also changes, both as an outcome and condition of human agency. If required they could, from their 'practical consciousness, provide an account, a rationalization of why they had acted under the specific prevailing circumstances. What people do, all the time, also is reflexively monitor their own and others' actions. Through their practical discursive consciousness they are capable of offering an explanation as to their' and other actions and motivations. People, also, reflexively audit what they, themselves, and others, are doing as means of adjusting their current and future behaviours and in their reactions to future circumstances. This form of human reflexivity is designated here as being "Replicative" in the sense that it facilitates, unconsciously, the creation and recreation of social systems. It is not an overt, standing back from the social system, but a reflexive one that acts to reproduce societal structures giving rise to 'familiar' patterns of human agency. This it does by enabling human beings to act and interact based on practical knowledge of how to act in the world which has been gained through reflexively monitoring how they and others act and interact appropriately under familiar social circumstances. It provides an individual with a sense of personal ontological security, a sense of being, within society. Each action and encounter, to use an oxymoron, is uniquely familiar. In so doing it both reproduces and reinforces the prevailing social structurated order.

\subsection{Structuration Theory and Information Systems Research}

Jones and Karsten (2008:127) in a recent review of 331 Information Systems articles that have drawn on Gidden's work concluded that there are significant opportunities for IS researchers to pursue structurational research that "engages sympathetically, yet critically with Gidden's work". Their review reiterates Gidden's rejection of objectivism and naturalistic approaches leading to concerns over some of the 
dominant interpretations and adaptations of Structuration Theory in IS research such as Adaptive Structuration Theory (DeSanctis and Poole, 1994) and the duality of technology (Orlikowski, 1992; Brooks, 1997). They emphasise that this should not be proscriptive however and identify three broad strands of use; application of structurational concepts, development and application of IS-specific versions of Structuration Theory and thirdly, critical engagement with Structuration Theory. This last strand relates to attempts to develop hybrid approaches such as combining Structuration Theory with other theories such as critical realism, soft systems methodology (Rose and Lewis, 2001), Actor Network Theory (Brooks and Atkinson, 2004) and also science and technology studies (Jones and Karsten, 2008). These hybrid approaches attempt to address some of the theoretical limitations and lack of empirical applications of Gidden's work within the field of IS. Jones and Karsten (2008) view the integration of Structuration Theory and Actor Network Theory to incorporate a more distinct emancipatory component (Brooks and Atkinson, 2004) as somewhat tautological; they highlight a view that a deeper reflection of Gidden's theory would allow for emancipatory change in every instant of action - due to the degree of agency and choice inherent within all human actors in every instant of action. In response to these critiques our focus therefore centres on the complementarity of Actor Network Theory to Structuration Theory and in particular the dimension of agency termed translation in ANT terms and the modality of problematization.

\section{ACTOR NETWORK THEORY: AN OVERVIEW}

Actor network theory (ANT), with its human and non-human equivalence, offers an interpretive framework as to how socio-technical 'humanchine' networks (humans and technologies as actors) convene, through translation, together at the behest of a prospective focal actor (Law and Hassard, 1999). This consists of Callon and Latour's 'moments of translation' namely: the initial '...problematization' of a particular situation by the focal actor, the gaining of putative actors' 'intéressemment' (interest) in addressing the problem, their subsequent 'enrolment' into the network and final mobilization necessary to becoming an actor within a hybridic sociotechnical network solution to that problem(Callon and Latour, 1981). 
The question that arises in this paper is: 'How do such (informated) humans and nonhumans (identified as 'humanchine' networks) come into being, persist and exhibit, in some instances, a multiplicity of forms of agency?' One theory that could account for this is the Actor Network Theory (ANT) of Callon, Latour and Law (Callon and Latour, 1981). But they and ANT, in its original form, cannot account for how these networks persist over time and space other than at the behest of some 'focal actor'. This focal actor has to constantly exercise their will in driving them and translating more actors into the network until it becomes increasingly consolidated and undifferentiated, or 'black boxed' and acting in line with the focal actors' interests. Latour says: "A black box contains that which no longer needs to be considered, those things whose contents have become a matter of indifference" (Callon and Latour, 1981).

An 'epistemological translation' of the two theories offered above into one hybridized framework, StructurANTion, this paper argues offers potential to account for how humanchine network reflexivity can be created through a melding of Giddens' Structuration Theory (Giddens, 1979,Giddens, 1984, Bryant and Jary, 1991) and the Actor Network Theory of Latour (Latour, 1996; Latour, 2005), Callon (Callon, 1986) and Law (Law and Hassard, 1999).

Additionally, Structuration Theory (ST) for the most part cannot account for technologies and non-human actors as anything other than resources whose role is to support human agency. Nor does it account for dramatic change in that network; even its deconstruction and replacement. A hybrid theoretical framework is therefore proposed, one that can account for how structurated networks can come into being and persist through time and space without the necessity of some focal actor driving them. Rather, a network that constitutes itself autopoietically (self organising). The two theoretical constituents and the theoretical hybrid that emerges from their melding together are explored in the following sections providing the rationale for the development of the StructurANTion framework. 


\section{THE STRUCTURATED HUMANCHINE NETWORK}

Human and machine or 'Humanchine networks' as the name suggests, are constituted out of humans and their agency acting in association with the behaviours of nonhuman actors of all kinds, whether they are artefacts or other phenomena. Such sociotechnical humanchines may consist of the single individual and a single artefact; e.g. the laptop and human user. Alternatively the network may encompass a whole enterprise including its people, rules and regulations, technologies and other nonhuman artefacts and resources, such as finances and plant. Networks of enterprise networks that spring up, such as a multinational corporation and its associated suppliers and customer organisations or the UK nationwide National Health Service (NHS), are also examples of humanchine networks. Institutional networks do not have to be commercial, e.g. the UK Parliament or a global charity. Other political parties and even radical groupings can be seen as networks of people, machines and non corporeal artefacts that collectively act in achieving some self-determined intent. All of these have information and its use at the centre of both their existence, persistence and their agency.

We suggest that Giddens' social ontology of social 'Structuration' helps to understand this. The StructurANTion Theoretical Framework (Brooks and Atkinson, 2004) has been developed in order to address some of the emancipatory and reflexivity issues inherent within either structuration or actor network theory applied in isolation.

This integrated theoretical framework posits that, just as humans are facilitated in their agency by having an innate capability to draw on the modalities of the social system structurated order within which they exist and which, through their actions (re)create, so do non-humans, technologies; albeit, in a limited form. However, there is no, ontological, symmetry between the two forms of actors with respect to their agency with respect to intent. Non humans unlike humans, to date, do not exhibit intentionality; rather they function when stimulated by external inputs and have access to some form of energy. Even sophisticated electronic avatars as yet do not exhibit volition; rather they behave in response to stimuli. However, it can be argued, that 
recently 'humanchine' hybrid simulations such as 'Second Life' (http://secondlife.com/) do appear to exhibit intent, through their mediation of human agency in a virtual environment.

Non-humans, machines and technologies of all kinds, in particular IS software applications and their technological infrastructures, will have 'structurated orders' inscribed in them during their development and implementation. These in turn will be further adjusted when they are translated into a network and used to carry out agency. In doing so they create and recreate the structurated order of the sociotechnical network, of which they and other human and non-human actors are constitutive parts.

These concepts, encapsulated in the StructurANTion framework are now explored within the context of a case study example concerning the use and adaptation of clinical information systems within the UK national health service. The aim is to demonstrate how networks persist and how the structurated order is recreated over time; being a complex set of interactions within the sociotechnical (humanchine) network rather than due to either technological (machine) or human and organisation factors resulting from any one distinct instrumental set of actions.

This case study sets out to explore the nature of reflexivity as a prominent feature of the 'structurated humanchine network' construct that is the ontological entity at the centre of the StructurANTion theoretical framework. This StructurANTion hybridic framework has been posited by the authors as a means of addressing the question: 'How do networks of humans and non-humans ontologically persist?' (Atkinson and Brooks, 2005; Atkinson and Brooks, 2003; Brooks and Atkinson, 2004). By what means do such networks do this without some 'focal actor' being continually present to translate the network and its actors in response to the multiplicity of problematizations that they continually face? The case explores a specific aspect of these humanchine networks, namely 'reflexivity'; both at the collective and the individual level. We suggest that an overt manifestation of human-machine reflexivity can be seen in the case of clinical 'audit'. This interpretive case study focuses on issues related to the development of a new form of patient led audit in which information is drawn from documented clinical information sources, NHS personnel and patient's experiences as well as training materials. 


\section{CASE STUDY: CLINICAL INFORMATION SYSTEMS AND AUDIT - SHEFFIELD PRIMARY CARE TRUST}

\subsection{Clinical Information Systems}

Clinical information systems have patient informational and care management services inscribed in their programming and data (through their programmes and data designed objects). These capture ongoing data about the patient, their disease, diagnosis, patient X-rays and Scans, current treatment, vital signs, drugs given and any potential patient 'abreactions' along with care outcomes and results. This can be done on an on-going basis at each consultation and include reports on tests and hospital interventions, mediated in the UK by NHS national information spine on which sit 38million patient records. The patient's admission and discharge from an episode of care in the healthcare setting - hospital or community - will also be recorded along with the clinician who authorized them.

In the UK, the intention is for each patient's history to be held within an EPR system within the healthcare organisation in the community and hospitals. This EPR record for a particular patient would include previous episodes of care, by whom, outcomes, medication allergies and contra-indications for pharmaceuticals. Within England this record (in summary) will be available within any primary and secondary health care organisation across the country via the NPfIT National spine. It will also be available and longitudinally updatable with each episode in the hospital or general practice. Inscribed in the data and functionality will be a model of clinical practices and patient care pathways for the treatment of the patient. These EPR, when used to facilitate care, provide care pathways/protocols for a given diagnosis which become active actors within a process of care. The clinical protocols define a process of care which will be enacted by doctors, nurses, paramedics, medical technologies and drugs along with medical and information technologies in order to deliver care to the patient. Reflexive compliance and deviance from the pathways that arise in caring for the patient will be captured and monitored by the clinical team and clinical technologies a heart monitor for example. Treatment and patient progress will be captured in the EPR against the diagnostic initiated care pathway protocol and the patient's 
designated care plan. This will be a component of the reflexive management of patient care.

\subsection{Clinical Audit}

Clinical Audit was introduced to the NHS in 1993. It is defined as: "a quality improvement process that seeks to improve patient care and outcomes through systematic review of care against explicit criteria and the implementation of change" (Scrivener et al., 2002).

Clinical audit draws on medical information systems as well as human experiences of care and has become a ubiquitous feature of health care settings worldwide. It is directed at providing clinicians' with a means of constantly improving both health care delivery and clinical outcomes against prescribed criteria. Clincial audit is viewed here as formalized and overt form of reflexivity (Giddens, 1984). Its very ubiquity, however, has also served to entrench the clinician and their interests at the centre of healthcare delivery networks along with their clinico-centric 'structurated order' within care settings. In the light of this phenomenon, the emancipatory structure, posited within the StructurANTion framework, is deployed here as a means of interpreting and exploring an alternative form of healthcare reflexivity: 'patient centred audit', in which patients have a more central role leading to the potential for better outcomes through more effective understanding, communication, diffusion, use and take-up of the clinical information available.

The currently accepted definition of clinical audit in the UK health service is as "a quality improvement process that seeks to improve patient care and outcomes through systematic review of care against explicit clinical criteria and the implementation of change. Aspects of the structure, processes, and outcomes of care are selected and systematically evaluated against explicit clinical care criteria. Any indicated, changes are implemented at an individual, team, or service level and then further monitoring is used to confirm improvement in healthcare delivery" (Scrivener et al., 2002, p1). Essentially this is an audit into healthcare practices and outcomes that seeks to identify the actual contribution to care according to types of patients and their clinical outcomes. It can be argued that this is a formalized form of reflexivity within the structurated actor network. The National Institute of Clinical Excellence (NICE) sets 
out principles for best practice in clinical audit using a circular model (Scrivener et al., 2002, see Figure 2).

The model begins by investigating what is the intended outcome of the health care services and/or clinical practice. An exploration of patient notes and clinical outcomes is then undertaken. This stage sometimes includes eliciting the patients' directly expressed

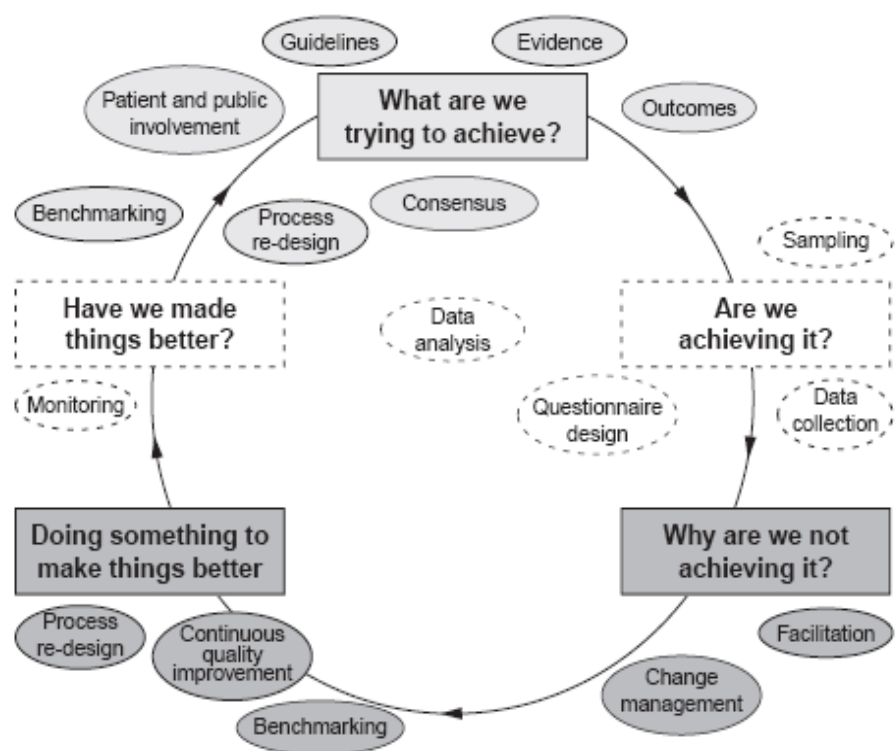

Figure 2. The clinical audit cycle (Scrivener et. al., 2002) experiences. It compares what is happening in terms of actual care delivery processes and outcomes with 'best practice' benchmarks; this may be about services and access to them or clinical practices and care outcomes. The benchmarks will be based on either in-house clinical audit, action research or wide service audits, or both. In the UK this can, also, come from the Ministry of Health, NICE or from the various clinical professions' Royal Colleges. Ways of improving care based on this comparison are identified and implemented. This can include changing existing forms of delivering clinical care practices and services or introducing new ways altogether.

The efficacy and effectiveness of the 'humanchine' (Atkinson and Brooks, 2005) care network and its outcomes is enhanced through audit, yet its incumbent structurated order is not changed; the clinician remains at the centre of the care humanchine network. One of the important areas that a clinical practice is expected and questioned about, by NICE, is the use of information systems in their role in evoking change in the delivery of care: "The organisation takes note of the needs of audit when developing information technology systems...Electronic information systems can contribute to audit in many ways, including: improving access to research evidence; 
identifying users; collecting data; prompting change through record templates; and enabling revised systems of care to be introduced" (Scrivener et al., 2002, p112).

As can be seen from the NICE definition (NICE, 2002), clinical audit is an overt manifestation of reflexivity aimed at surfacing and then addressing issues in order to improve the delivery and outcomes of clinical care. Until recently clinical audit was undertaken manually. Patient paper notes were systematically extracted from their filing cabinets within the hospital or general practice records rooms and analysed. This meant that clinical audit was a labour intensive process that took staff away from the front line of delivering care. However, over the past 15 years the ubiquitous introduction of information technology (IT) and electronic patient records (EPR) throughout healthcare has meant that the sampling (either random or stratified) of personal and/or epidemiological characteristics of patients across hospital or primary care populations has been far easier to facilitate. Such sampling could be for patients with particular epidemiological characteristics: age and/or sex and/or location or even occupation or a combination for a particular condition - diabetics for example, or depression or those on a particular treatment, such as tamoxifen or beta blockers. Alternatively it could relate patient access and quality of services in the NHS. The completeness of patient records is also potentially a subject for clinical audit particularly if there is a specific requirement, such as in a teaching practice for GP students and trainees. Clinical governance, with clinical audit at its centre, using information technologies is an important aspect of ensuring the quality and the up to date delivery of care against evidence based medical standards, the latter stemming from medical research within the UK National Institute for Clinical Excellence (NICE) and the Cochran Centre (http://www.cochrane.org). Clinicians, GPs for example, through their Royal College, (http://www.rcgp.org.uk) have to revalidate themselves on a regular basis and are also subject to professional reflexivity by their peers.

An alternative to stratified sampling could be that of randomly selected patient records. Within data capture and collection within the process of clinical audit, the role of information systems can be identified as (Smith, 2005)

- Patient registers are used to identify patients, but registers can be incomplete. 
- Although clinical records are frequently used as the source of data, they are often incomplete. The collection of data from several sources can help to overcome this problem.

- When collecting data, a carefully developed data abstraction tool is recommended. Training data abstractors can improve data consistency.

- Electronic information systems can contribute to audit in many ways, including: improving access to research evidence; identifying users; collecting data; prompting change through record templates; and enabling revised systems of care to be introduced. (emphasis added)

\section{CASE ANALYSIS: USING STRUCTURANTION TO EXAMINE CLINICAL AUDIT}

\subsection{Emancipatory Reflexivity in Informated Healthcare Networks}

Replicative clinical reflexivity in healthcare is directed towards continuously improving, through audit, clinical practice and serves to both enhance care and entrench the incumbent medico-centric structurated order. It reproduces the role and status of the professional human and the organisationally owned non-human actors (including information technologies and systems) within the health care structurated network. The consequences of this are that through traditional clinical led audit it is the clinicians, rather than patient, who benefit immediately from any audit. This does not deny that the patient may benefit from the clinical audit in the care they are given, but it will be mediated through the clinician and their practices. The opportunity for reflexivity within the structurated order of the care network is, therefore, facilitated through the clinicians' evocation of the 'structure of Domination'. This enables them to authorize which people should be part of the clinician led audit, what their roles are and the allocation of the tools and techniques associated with it. It also determines who will be the immediate beneficiary of the findings of that audit, namely the clinician. The audit will be linguistically mediated (controlled) through the use of clinical terminology and coding (SNOMED (NHS, 2007)) rather than lay language of non-clinicians. The clinician will also be legitimized in their role as leader of the audit process, and decide the participants in it and the immediate beneficiary of what is revealed by it with respect to the provision of care. The patient will be legitimized in 
their role as a passive participant or contributor to the audit as an experiential information provider. They, the patient, in ANT terms, will be translated and enrolled into the network by the clinical audit lead focal actor as provider of information and as a passive care recipient.

While the audit may improve clinical care it does not - of necessity - seek to effect changes in the relationships and status of actors under the existing organisational conditions i.e. it does not mobilize the emancipatory structure to problematize and translate the healthcare humanchine network's incumbent structurated order. Rather it, most likely replicates it. Patient's contribute to the audit and its outcomes, by proxy through their notes or, at most by being interviewed, but do not take an active part in it, nor in the subsequent translating of the care network and the clinical practices within it. Emancipatory reflexivity, on the other hand, seeks to facilitate change that reconfigures the power relationships in the network; both in terms of conducting the audit and in affecting change within the healthcare network as a result of it - both of which have the patient as the focal actor.

Sometimes, as in this case, the evocation of the Emancipatory structure actually results in the complete deconstruction of the incumbent network along with its current structurated order. Therefore it is replaced by another network. This is one in which the inequalities that previously existed are overturned. On the other hand the network persists, but the structurated order of the network is substantively if not completely transformed. Drawing on the translatory language of ANT: the situation in the incumbent humanchine network of people and artefacts is problematized and possible actors who would form a new or transform the incumbent network may be identified.

\subsection{Problematization: the Clinical Audit Patient Panel in Sheffield PCT}

The Clinical Audit Patient Panel (CAPP) was formed as a new development within Sheffield Primary Care Trust to provide a more patient empowered approach to clinical medical audit. The focal actor (and main instigator) of this new development, Challens (Challans, 2007) intuitively drew on the Emancipatory structure to problematize the incumbent network and its clinico-centric structurated order, subsequently migrating into agency. "I've worked in quality improvement and clinical 
audit for over five years and during this time I've enjoyed exploring new ways of working with staff to implement evidence based medicine. One day I thought, hang on a minute-improving the quality of care through clinical audit is for staff and patients. And so I realised we should give patients the opportunity to be involved in improving and developing services as well as staff. From this spontaneous idea, we created the Clinical Audit Patient Panel (CAPP) in Sheffield.” As a result of what can be interpreted as an emancipatory, 'epiphany', Challans has sought to deconstruct the current dominant medico-centric reflexivity of the primary care trusts' incumbent structurated order that was, at the time, clinical audit. The 'mission' was to both challenge and complement it with one that had the patient and their interests at the centre of the reflexive process, both metaphorically and to a degree literally. It is the proposition here that, through the evocation of the Emancipatory structure, she sought to problematize the audit process as being over medicalized and serving primarily the clinicians interests. Challans translated the existing network's structurated order from one having the clinician as its focal actor to one having the patient in the role. To that effect she placed an advertisement in the local newspaper for people from the community to become members of the Clinical Audit Patient Panel. Establishing the Sheffield Clinical Audit Patient Panel (CAPP http://www.networks.nhs.uk/forums/).

Challans (Challans, 2007) afforded the opportunity to anyone who joined it to:

- "work with and actively engage patients, carers and the public in clinical audit and quality improvement

- empower patients as our auditors

- promote patient-staff partnerships to improve services

- provide training and support to patients involved in CAPP

- improve our Trust's performance on Patient and Public Involvement (PPI) forums and clinical audit."

In addition, "The panel will advise, support and improve clinical audit activity within the trust and it will enable service user's and carer's perspectives to be included in evaluating quality and to identify opportunities for improvement. Members can be actively involved in all phases of the project from initiation to completion." 
From the StructurANTion perspective it can be seen that the process leading to the establishment of the Sheffield CAPP was to be a real world manifestation of an incumbent actor healthcare networks' evocation of its inherent emancipatory structure. Initially this entailed a problematization of the clinician centred approach to audit and any resulting changes. This was followed by the deconstructing of audit as being the sole prerogative of the clinicians within the care network. In turn, this led to the setting up of a patient centric audit network. The evocation, by Challans, of the incumbent networks' Emancipatory Structure, translated the existing overt reflexivity of the care process, in the form of clinician centric audit, to one that was either wholly patient centric, or one in which they and their interests were overtly and powerfully present . In so doing the structurated order of the reflexivity of the incumbent clinicocentric healthcare network's structurated order was also challenged to overtly include the patient interests. The dominant clinico centric structurated order of the incumbent health services reflexivity, audit, was translated such that it became also patient centric. In doing so the structurated order of the care network was, to a marked degree, also translated.

A number of clear lessons were learnt from this evocation of the Emancipatory structure as reported by Challans (Challans, 2007). Firstly, that "Clinical audits can benefit by involving healthcare professionals and patients". Secondly... "Patients may disclose more about their experiences to other patients than to healthcare professionals". Thirdly, "Patients may disclose more about their experiences to other patients than to healthcare professionals". Fourthly, "Professional staff need reassurance that the contribution of patients will not undermine their role or contribution". Fifth and lastly "The patient panel can contribute to risk management and raise awareness of patient safety issues." From an IS perspective 'How then did information systems as actors both play a part in facilitating the evocation and enactment of the Emancipatory structure inherent within the hospitals organisational structurated order and, in doing so, how did they change it?'

At the heart of what Challans (Challans, 2007) was doing, and which expresses the evocation of the Emancipatory structure, was to translate, through reflexivity what is a clinic-centric reflexive process in the form of audit with its use of clinical information 
systems at its centre, to one in which the experiences of patient panels and the information they could provide in tandem with this clinical audit process was facilitating a process of more overt reflexivity. Both patients and clinicians could learn from this practice and, as a result enhance the delivery of care to patient.

In theoretical terms, the existing systems of control, organisation and structural order are being consolidated through a 'replicative' process of reflexivity. It is one in which the existing "clinic-centric" health care network (a system consisting of individuals, teams, organisations interacting with multiple technologies) is maintained intact, whilst clinical practices and hopefully outcomes are improved.

Therefore, although patients may have 'an involvement' it is not they who problematize a care situation and reflexively initiate and scope the audit, nor do they conduct it (see Figure 1). There is a "replicative reflexivity", of the incumbent structurated order (rather than the emancipatory one in which the patient holds the reigns) with the information technology and systems complicit in this in capturing and/or providing of information for the audit. It is not the patient that initiates the audit; but the clinician. The patients, or rather the hospitals' patient records and treatment, are the subject of the audit. Even though they serve to contribute to the audit they don't effect change in the patient's relationship with the health service; they remain 'the patient' who waits for the service. In StructurANTion terms the 'structurated order' of the network remains intact and unchanged via the audit. Indeed the audit may serve to consolidate the structurated order of a network further, to 'black box' it (Latour, 2005) further until the network becomes completely consolidated and undifferentiated.

\section{CONCLUSIONS}

A sociotechnical exploration, using the StructurANTion framework into information systems within real world setting has been carried out here at two levels, one ontological and the other epistemological. Ontologically the question was: how could the technical component of information systems, as actors, be translated and aligned along with human actors (patients, managers and clinicians) to facilitate a transition 
from a medico-centric reflexivity, in the form of clinical audit, to patient-centric audit. Further, how then did this affect, autonomic changes in the healthcare network's structurated order? The case explored here revealed that while there was a shift in the structurated order from clinician to patient centred with respect to audit, it was one of accommodation rather than a totally transformational one. The audit panel of patients was a mechanism facilitating the information found in the 'voice' of the patient alongside the clinical patient record as a component of reflexivity within the wider healthcare network. It had an emancipatory component in that patients played an active and, indeed prominent role, within the audit process. In addition it was they who set out what ought to be audited. Unlike previously, where it was the clinician and their structurated order that was dominant within the healthcare network. This included the selection of the areas of care chosen for audit as well as who was conducting the audit. In that sense it was emancipatory and information was a major component in facilitating that translation of the network.

This did not lead to changes in the overall health care humanchine networks structurated order. It was not an occasion in which the clinicians' ability to control and allocate resources of care was displaced. They continued to communicate through clinical discourses and were legitimised through their professional status to deliver and exercise control over the healthcare humanchine network. Rather, from the StructurANTion perspective, this was a manifestation of the evocation of the Emancipatory structure. In this instance by non-clinical actors, lay members of the public and the Clinical Effectiveness Manager within the Healthcare network of South Sheffield. From a StructurANTion perspective, it was an instance of inclusivity in the care provision network. One of translating a network by drawing upon an emancipatory, rather than replicative reflexivity, so as to empower the patient to have their legitimate voice heard, in a language of their own, about their individual and collective care provision. It was an instance of the patient being legitimized as capable of reflecting upon and effecting change within the clinical care network, having accrued power to do so through their being translated into and in turn translating the South Sheffield care audit network. It offered the potential to be even more emancipatory, if further change in the structurated order of the care management and delivery network was translated as a result of their inclusion. This could be one in which both the patient and clinician become translated in such a way that they 
reflexively collaborate together on how best to deliver care, including clinical decision making, to the individual patient, specific groups of patients and the population at large. Penston (2007) refers to this as, "reflexive concordance" which was being achieved by the patient, clinicians and management actors at the point of care. In addition, it was facilitated by a patient/physician information system and clinical records being made available and accessible to all engaged in the audit process. This, if it were to be realized, would of course entail a joint "reflection upon reflection" between the patient and clinician, facilitated through an evocation of the Emancipatory structure, of the nature of an inclusive care network in the light of the existing clinico centric network.

In terms of contribution to Information Systems theory this exploration of the use of the hybrid framework, StructurANTion, has responded to the call (Jones and Karsten, 2008) for a greater emphasis on empirical application and extension of structuration theory and makes some progress towards adding to the cumulative body of knowledge. The discussion of the case study, especially with a focus on the reflexive potential of using the integrated framework, has provided greater insight into the application of both Structuration and Actor Network theoretical concepts in practice and especially how emancipatory design principles might be achieved in complex and sensitive professionally driven environments (where there are high levels of obstacles in place to evoke change due to professional and in this case clinico-centric power and domination control structures). The particular focus on the emancipation and reflexive component is a direct response to propositions (Jones and Karsten, 2008) that Gidden's Structuration Theory implicitly incorporates these ideals. Our concern is to more overtly surface this component in a more directly actionable form to assist and enable individual and group level human agency (through the modality of communication) to challenge and change existing structures of domination and legitimation.

Our work also responds to more recent calls to develop robust design theories for Information Systems research and practice (Gregor and Jones, 2007). Future work may be able to explore the potential of the StructurANTion framework to add a more socially informed dimension to existing IS development, implementation and adoption methodologies and projects. This greater theoretical depth and insight would 
assist in raising the IS discipline above what Gregor and Jones (2007) terms 'the craftlevel'.

\section{References}

Atkinson, C. J. and Brooks, L. (2005) In the Age of the Humanchine, International Conference on Information Systems (ICIS) AIS, Las Vegas.

Brooks, L. (1997) Structuration Theory and New Technology: Analyzing Organizationally Situated Computer-Aided Design (CAD), Information Systems Journal, Vol 7, No. 2, pp. 133-151.

Atkinson, C. J. and Brooks, L. S. (2003) StructurANTion: A Theoretical Framework for Integrating Human and IS Research and Development, Americas Conference on Information Systems (AMCIS) (Ed, Truex, D.), Tampa, USA.

Brooks, L. and Atkinson, C. J. (2004) StructurANTion in Research and Practice: Representing Actor Networks, their Structurated Orders and Translations, In Information Systems Research: Relevant Theory and Informed Practice, IFIP 8.2 Conference(Eds, Kaplan, B., Truex III, D., Wastell, D., Wood-Harper, T. and DeGross, J. I.) Kluwer Academic Publishers, Boston, pp. 389-409.

Bryant, C. G. A. and Jary, D. (1991) Giddens' theory of structuration : a critical appreciation, Routledge, London.

Callon, M. (1986) Some Elements of a Sociology of Translation: Domestication of the Scallops and the Fishermen of Saint Brieuc Bay, In Power Action and Belief: a new Sociology of Knowledge? Sociological Review Monograph, Vol. 32 (Ed, Law, J.) Routledge and Kegan Paul, London, pp. 196-233.

Callon, M. and Latour, B. (1981) Unscrewing the Big Leviathan: how actors macrostructure reality and how sociologists help them to do so, In Advances in Social Theory and Methodology: Toward an Integration of Micro- and Macro-Sociologies.(Eds, Knorr-Cetina, K. D. and Cicoure, A. V.) Routledge and Kegan Paul, Boston, Mass, pp. 277-303.

Challans, E. (2007) Patients and clinical audit - a marriage made in Sheffield?, Available at: http://www.saferhealthcare.org.uk/IHI/Topics/ManagingChange/SafetyStories/ Patients+and+clinical+audit.htmNational Patient Safety Agency.

Chambers, R., Drinkwater, C. and Boath, E. (2003) Involving Patients and the Public: How to Do It Better, Oxford Radcliffe Medical Press.

DeSanctis, G. and Poole, M.S. (1994) Capturing the Complexity in Advanced Technology Use: Adaptive Structuration Theory, Organization Science, Vol.5, No. 2, pp. 121-147.

Giddens, A. (1979) Central Problems in Social Theory, Macmillan, Basingstoke, UK.

Giddens, A. (1984) The Constitution of Society: outline of the theory of structuration, Polity, Cambridge.

Giddens, A. (1990) The Consequences of Modernity, Polity in association with Blackwell.

Giddens, A. (1991) Structuration Theory: Past, Resent and Future, In Giddens' Theory of Structuration: A Critical Appreciation(Eds, Bryant, C. G. A. and Jary, D.) Routledge, London.

Gregor, S. and Jones, D. (2007) The Anatomy of a Design Theory, Journal of the Association for Information Systems, Vol.8, No.5, pp.312-335. 
Jones, M.R. and Karsten, H. (2008) Gidden's Structuration Theory and Information Systems Research, MIS Quarterly, Vol.32, No. 1, pp. 127-157.

Latour, B. (1996) Aramis or the Love of Technology, Harvard University Press.

Latour, B. (2005) Reassembling the social: an introduction to actor-network-theory, Oxford University Press, Oxford ; New York.

Law, J. and Hassard, J. (1999) Actor network theory and after, Blackwell, Oxford ; Malden, MA.

NHS (2007) SNOMED CT - the language of the NHS Care Records Service: A guide for NHS staff in England, Available at:

http://www.connectingforhealth.nhs.uk/systemsandservices/data/snomed/snom ed-ct-a.pdf.

NICE (2002) Principles for Best Practice in Clinical Audit, National Institute of Clinical Excellence (NICE),

Orlikowski, W.J. (1992) The Duality of Technology: Rethinking the Concept of Technology in Organizations, Organization Science, Vol.3, No.3, pp. 398-427.

Penston, J. (2007) Patients' preferences shed light on the murky world of guidelinebased medicine, Journal of Evaluation in Clinical Practice, 13 154-159.

Rose, J. and Lewis, P. (2001) Using Structuration Theory in Action Research: An Intranet Development Project, in Realigning Research in Practice in Information Systems Development: The Social and Organizational Perspective, N.L. Russo, B. Fitzgerald and J.D. Gross (eds.) Boston: Kluwer Academic Publishers, pp. 273-295.

Scrivener, R., Morrell, C., Baker, R., Redsell, S., Shaw, E., Stevenson, K., Pink, D. and Bromwich, N. (2002) Principles for Best Practice in Clinical Audit, Radcliffe Medical Press.

Smith, C. (2005) Clinical Audit Strategy 2005/2006, Heart of Birmingham Teaching Primary Care Trust.

Waring, T. and Wainwright, D. (2002) Communicating the Complexity of ComputerIntegrated Operations: An innovative use of process modelling in a North East Hospital Trust, International Journal of Operations and Production Management - Special Issue on Healthcare Systems, Vol 22, No.4, pp. 394411

\section{Acknowledgements}

The authors would personally like to thank Ms Debra Canning and Ms Emma Challans of Sheffield PCT (http://www.sheffieldpct.nhs.uk/) \& Ms Jan Ellen Chair of the Patient Panel for their information and comments in respect of this paper. 